\title{
Ovarian Cystadenocarcinoma with an Osteosarcoma Component
}

\author{
S. Sakhri esp Boulhart * \\ Head of Medical Oncology Department, Laghouat, Algeria.
}

*Corresponding author: S. Sakhri esp Boulhart, Head of Medical Oncology Department, Laghouat, Algeria.

Received date: June 16, 2021; Accepted date: July 12, 2021; Published date: July 21, 2021

Citation: S. Sakhri esp Boulhart, (2021). Impact OF Covid-19 on Several Industries in Context with the Sperm Bank Industry. J Clinical Research and Reports, 8(4); DOI:10.31579/2690-1919/184

Copyright: () 2021 S. Sakhri esp Boulhart. This is an open access article distributed under the Creative Commons Attribution License, which permits unrestricted use, distribution, and reproduction in any medium, provided the original work is properly cited.

Abstract
Ovarian cystadenocarcinoma with an osteosarcoma component, is a very rare tumor. We aimed to describe
a case of an osteosarcoma arising in an ovarian squamous cell carcinoma.
Keywords: ovarian cystadenocarcinoma; osteosarcoma component; fibrosarcoma; MMMT;
vesicouterine excavation; immunohistochemical analysis

\section{Introduction}

Ovarian, cystadenocarcinoma with an osteosarcoma component (OCS) also known as malignant mixed müllerian tumor (MMMT), is a very rare gynecological malignancy accounting for $1-3 \%$ of ovarian malignancies [1]. OCS is a mixed tumor composed of carcinomatous and sarcomatous components. The sarcomatous component may be either homologous, including endometrial stromal sarcoma, fibrosarcoma and leiomyosarcoma, or heterologous. We report a case of ovarian cystadenocarcinoma with an osteosarcoma component.

\section{Case presentation:}

A 63-year-old woman presented a tumor in the abdomen in December 2020. The tumor was restricted. Imaging findings, including computed tomography and magnetic resonance imaging, revealed a multilocular cyst tumor. Imaging also showed that the patient had massive ascites.

Total abdominal hysterectomy, bilateral adnexectomy, omentectomy, lymphadenectomy (pelvic and para-aorta), peritonectomy of vesicouterine excavation, resection of disseminated lesion of Douglas' pouch and a biopsy of the colonic mesentery were performed without residual disease.

The immunohistochemical analysis showed that the sarcomatous component was positive for vimentin, alpha

SMA and CD10 and negative for AE1/AE3, CK7, CK20, desmin, CD31, CD34, AFP, hCG, HMB-45, S-100 and factor VIII; the Ki-67 (MIB-1) index was $30 \%$.

For cystadenocarcinoma the immunohistochemical analysis showed positivity for AE1/AE3 and EMA and negativity for PAS, ALB, CK7, CK20, vimentin, alpha SMA, desmin, CD10, CD34, AFP, HCG, CD56 and synaptophysin,chromogranin; the Ki-67 (MIB-1) index was $25 \%$.
Postoperatively, the patient was treated with six cycles of combination chemotherapy with paclitaxel and carboplatin as adjuvant therapy. The patient was free of disease at the 7-month follow-up consultation.

\section{Discussion}

OCS is an extremely rare tumor among ovarian cancers, with a frequency of occurrence of 1-3\% [1]. Carcinosarcomas of the female genital tract are often found after menopause at a median age of 60 to 70 years old. OCS has a worse survival rate than high-grade ovarian cancer at the same FIGO stage, with a median overall survival ranging from 7 to 27 months [1].

Histologically, OCS contains both carcinomatous (malignant epithelial) and sarcomatous (mesenchymal) components. The sarcomatous component may consist of homologous tissue that are native to the ovary or heterologous tissue not native to the ovary. The optimal treatment of OCS remains uncertain due to this tumor's rare occurrence. Many cases of OCS undergo surgical treatment and chemotherapy, similar to epithelial ovarian cancer [2]. In one of the larger studies, including 50 patients with OCS, the disease-free survival for patients with complete resection was 19 months. The overall survival of complete resection and optimal and suboptimal surgery is reportedly 47, 18 and 8 months, respectively [3]. Optimal surgical cytoreduction, including total abdominal hysterectomy, bilateral adnexectomy, omentectomy, pelvic and para-aortic lymph node dissection, and tumor debulking is important for improving the prognosis of OCS. Following debulking surgery for OCS, adjuvant chemotherapy is typically recommended. However, there is no consensus regarding the most effective regimen for such a rare malignancy [4]. In this it was difficult to decide on the chemotherapy regimen. The prognosis of ovarian squamous cell carcinoma is extremely poor compared with that of typical epithelial ovarian cancer, which has a 5 -year survival rate of $50 \%$ in stage I, $25 \%$ in stage II, $12 \%$ in stage III and $0 \%$ in stage IV [5]. In OCS, similar to epithelial ovarian cancer, 
platinum-based chemotherapy is considered a key drug. Combination chemotherapy, such as carboplatin and paclitaxel or ifosfamide, exhibits a higher response rate than single-agent platinum chemotherapy [5]. Several studies have described the clinical effectiveness of combination chemotherapy with carboplatin and paclitaxel in ovarian squamous cell carcinoma [6,7]. Given the above findings, combination chemotherapy with carboplatin and paclitaxel was selected in the present case.

\section{Conclusion}

This is a rare report of Ovarian cystadenocarcinoma with an osteosarcoma. Combination chemotherapy with paclitaxel and carboplatin may be an effective choice as adjuvant. Further study is required in order to identify the best principles of treatment and how to manage the new cytotoxic drug, targeted therapy and immunotherapy for OCS.

\section{References}

1. Berton-Rigaud D, Devouassoux-Shisheeboran M, Ledermann JA, et al. (2014). Gynecologic Cancer InterGroup (GCIG) consensus review for uterine and ovarian carcinosarcoma. Int $\mathrm{J}$ Gynecol Cancer. 2014; 24:S55-60.
2. Rutledge TL, Gold MA, McMeekin DS, Huh WK, Powell MA, Lewin SN, Mutch DG, Johnson GA, Walker JL, Mannel RS. (2006). Carcinosarcoma of the ovary-a case series. Gynecol Oncol. 2006; 100:128-132.

3. 3.Rauh-Hain JA, Growdon WB, Rodriguez N, Goodman AK, Boruta DM 2nd, Schorge JO, Horowitz NS, del Carmen MG. (2011). Carcinosarcoma of the ovary: a case-control study. Gynecol Oncol. 2011; 121:477-481.

4. Shylasree TS, Bryant A, Athavale R. (2013). Chemotherapy and/or radiotherapy in combination with surgery for ovarian carcinosarcoma. Cochrane DatebaseSyst Rev. 2013; 28:CD006246.

5. Kashimura M, Shinohara M, Hirakawa T, Kamura T, Matsukuma K. (1989). Clinicopathologic study of squamous cell carcinoma of the ovary. Gynecol Oncol. 1989; 34:75-79.

6. Duska LR, Garrett A, Eltabbakh GH, Oliva E, Penson R, Fuller AF. (2002). Paclitaxel and platinum chemotherapy for malignant mixed müllerian tumors of the ovary. Gynecol Oncol. 2002; 85: 459-463.

7. Eltabbakh GH, Hempling RE, Recio FO, O'Neill CP (1998). Remarkable response of primary squamous cell carcinoma of the ovary to paclitaxel and cisplatin. Obstet Gynecol. 1998;91:844846.
This work is licensed under Creative Commons Attribution 4.0 License

\section{To Submit Your Article Click Here: Submit Manuscript}

DOI: $10.31579 / 2690-1919 / 184$
Ready to submit your research? Choose Auctores and benefit from:

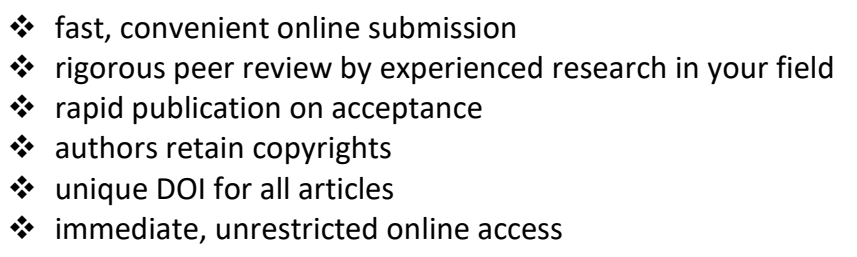

At Auctores, research is always in progress.

Learn more auctoresonline.org/journals/journal-of-clinical-research-andreports 